\title{
Molecular characterization of amikacin, kanamycin and capreomycin resistance in M/XDR-TB strains isolated in Thailand
}

Angkanang Sowajassatakul ${ }^{1}$, Therdsak Prammananan ${ }^{2,4}$, Angkana Chaiprasert ${ }^{3,4}$ and Saranya Phunpruch ${ }^{*}$

\begin{abstract}
Background: The emergence of multidrug-resistant tuberculosis (MDR-TB) and extensively drug-resistant tuberculosis (XDR-TB) makes the treatment and control of tuberculosis difficult. Rapid detection of drug-resistant strains is important for the successful treatment of drug-resistant tuberculosis; however, not all resistance mechanisms to the injectable second-line drugs such as amikacin (AK), kanamycin (KM), and capreomycin (CAP) are well understood. This study aims to validate the mechanisms associated with AK, KM, and CAP resistance in M. tuberculosis clinical strains isolated in Thailand.
\end{abstract}

Results: A total of 15,124 M. tuberculosis clinical strains were isolated from 23,693 smear-positive sputum samples sent from 288 hospitals in 46 of 77 provinces of Thailand. Phenotypic analysis identified 1,294 strains as MDR-TB and second-line drugs susceptibility was performed in all MDR-TB strains and revealed 58 XDR-TB strains. Twenty-nine KM-resistant strains (26 XDR-TB and 3 MDR-TB) could be retrieved and their genes associated with AK, KM, and CAP resistance were investigated compared with $27 \mathrm{KM}$-susceptible strains. Mutation of the rrs (A1401G) was found in 21 out of 29 KM-resistant strains whereas mutations of eis either at C-14 T or at G-37 T were found in 5 strains. Three remaining KM-resistant strains did not contain any known mutations. Capreomycin resistance was determined in 28 of 29 KM-resistant strains. Analysis of tlyA revealed that the A33G mutation was found in all CAP-resistant strains and also in susceptible strains. In contrast, the recently identified tlyA mutation T539G and the novel Ins49GC were found in two and one CAP-resistant strains, respectively. In addition, our finding demonstrated the insertion of cytosine at position 581 of the tap, a putative drug efflux encoding gene, in both KM-resistant and KM-susceptible strains.

Conclusions: Our finding demonstrated that the majority of KM resistance mechanism in Thai M. tuberculosis clinical strains was rrs mutation at A1401G. Mutations of the eis promoter region either at C-14 T or G-37 T was found in 5 of 29 strains whereas three strains did not contain any known mutations. For CAP resistance, 3 of 28 CAP-resistant strains contained either T539G or Ins49GC mutations at tlyA that might be associated with the resistant phenotype.

Keywords: Tuberculosis, Second-line drug, Resistance, Aminoglycoside

\section{Background}

Tuberculosis (TB) is a global public health problem caused by an infection with Mycobacterium tuberculosis. There were approximately 9 million new cases of TB and 1.3 million deaths in 2012 [1]. The emergence of multidrug-resistant TB (MDR-TB; resistance at least to isoniazid and rifampicin) and extensively drugresistant TB (XDR-TB; MDR-TB plus resistance to any

\footnotetext{
* Correspondence: kpsarany@kmitl.ac.th

'Department of Biology, Faculty of Science, King Mongkut's Institute of

Technology Ladkrabang, Bangkok 10520, Thailand

Full list of author information is available at the end of the article
}

fluoroquinolones and one of the second-line injectable drugs, amikacin, kanamycin and capreomycin) remains a global health problem that hinders the prevention, treatment, and control of TB. In Thailand, approximately 80,000 new TB cases were notified in 2012 and MDR-TB appeared in $1.7 \%$ and $35 \%$ of new TB cases and previously treated TB cases, respectively [1].

Rapid identification of drug-resistant strains is one of the major strategies for fighting against TB. Molecularbased methods for detection of drug resistance genes have been shown to be a promising method for identification of drug-resistant strains; for example, the Xpert 
MTB/RIF assay and the GenoType MTBDRplus assay have been successfully used to identify rifampicin-resistant M. tuberculosis and MDR-TB, respectively [2-7]. In contrast, knowledge concerning resistance mechanisms of the second-line anti-TB drugs is still limited. Better understanding of the resistance mechanisms of these drugs could lead to the development of a high sensitive test for detection of the resistance genes and also promote the use of molecular-based methods for screening the strains resistant to second-line drugs, including the XDR-TB strain.

The aminoglycosides amikacin (AK) and kanamycin (KM) are the second-line injectable drugs used to treat MDR-TB. The drugs bind to $16 \mathrm{~S}$ rRNA in the 30S small ribosomal subunit and inhibit protein synthesis [8]. $\mathrm{Mu}-$ tations in the rrs gene encoding 16S rRNA are associated with high-level drug resistance in M. tuberculosis; the rrs A1401G mutation is the most frequently reported mutation and has been identified in 30 to $90 \%$ of KMresistant $M$. tuberculosis strains [9-12].

Recently, overexpression of the aminoglycoside acetyltransferase-encoding gene, eis, has been associated with a low-level resistance to KM $[13,14]$. This overexpression resulted from either point mutations in the promoter region of the eis gene or mutations in the $5^{\prime}$ untranslated region (UTR) of the whiB7 gene, which encodes a putative regulator of the eis gene. This type of eis promoter mutation was found in $26-80 \%$ of $\mathrm{KM}$ resistant $M$. tuberculosis clinical strains [14-17]. However, some resistant strains do not contain any known mutations. Other possible resistance mechanisms, including the presence of drug efflux pumps or enzymes that can inactivate the drug or modify the drug target, have been proposed. Tap, a putative efflux pump that was originally described in Mycobacterium fortuitum, conferred resistance to tetracycline and aminoglycosides when introduced into M. smegmatis [18]. A homolog of this protein (Rv1258c) has been found in M. tuberculosis and functions under the control of WhiB7 [19].

Previous studies demonstrated that the rrs mutation conferring KM resistance also exhibited the crossresistance to capreomycin (CAP), a cyclic polypeptide antibiotic [20,21]. Capreomycin binds across the $23 \mathrm{~S}$ rRNA helix 69 and 16S rRNA helix 44 of the ribosome, resulting in inhibiting the protein synthesis [22,23]. Resistance to CAP has been reported to correlate with the gene encoding 2'-O-methyltransferase (tlyA) [24], although it is not a sensitive genetic marker for CAP resistance due to the infrequent finding [16]. TlyA functions by methylating at nucleotide $\mathrm{C} 1409$ in helix 44 of 16S rRNA and nucleotide C1920 in helix 69 of 23S rRNA. Loss of this methylation confers resistance to CAP and viomycin [23].

The present study aimed to validate all reported mechanisms associated with AK, KM and CAP resistance in
M/XDR-TB clinical strains isolated in Thailand. Moreover, these mechanisms were also investigated in KMsusceptible strains.

\section{Results}

Amikacin- and kanamycin-resistant phenotypes

A total of $15,124 M$. tuberculosis clinical strains were isolated from 23,693 smear-positive sputum samples sent from 288 hospitals in 46 of 77 provinces of Thailand. Phenotypic analysis identified 1,294 strains as MDR-TB. Using the standard proportion method on M7H10 agar with a single concentration of $1 \mu \mathrm{g} / \mathrm{ml}$ for ofloxacin and $6 \mu \mathrm{g} / \mathrm{ml}$ for $\mathrm{AK}$ and $\mathrm{KM}, 58$ strains were defined as XDR-TB. Twenty-nine KM-resistant strains (26 XDR-TB and 3 MDR-TB) could be retrieved and available for further investigation on the genes associated with $\mathrm{AK}, \mathrm{KM}$, and CAP resistance (Additional file 1: Table S1). MICs of AM, KM, and CAP were determined, and the results are summarized in Table 1.

\section{Molecular analysis of genes associated with amikacin, kanamycin, and capreomycin resistance}

The 16S rRNA genes (rrs) of all 29 KM-resistant strains were amplified and sequenced. The results revealed a point mutation at nucleotide position $1401(A \rightarrow G)$, which corresponds to position 1408 of the Escherichia coli rrs gene, in 21 strains (Table 1). Almost all strains harboring the rrs A1401G mutation showed a high-level of resistance to both AK and KM, with MICs $>64 \mu \mathrm{g} / \mathrm{ml}$, whereas variable MICs were found against CAP, with ranging from 4 to $>64 \mu \mathrm{g} / \mathrm{ml}$ (Table 1 ).

The nucleotide sequences of coding regions and the putative promoter regions of eis (Rv2416c) and whiB7 (Rv3197A), coding regions of tap (Rv1258c) and tlyA (Rv1694), were investigated in all KM-resistant clinical strains and $27 \mathrm{KM}$-susceptible clinical strains. No mutation of all investigated genes (except for tap) was found in 21 strains with rrs mutation. For the remaining eight KM-resistant strains, point mutations at either position $-14(\mathrm{C} \rightarrow \mathrm{T})$ or position $-37(\mathrm{G} \rightarrow \mathrm{T})$ upstream of the eis gene were observed in 5 strains; the $\mathrm{C}-14 \mathrm{~T}$ mutation was found in 4 strains, whereas the G-37 T mutation was found in only one strain (Table 1 and Additional file 1: Table S1). No eis mutations were found in 27 KM-susceptible strains (Table 1 and Additional file 2: Table S2). Sequence analysis of the whiB7 gene and its promoter region did not reveal any mutations in all KMresistant and -susceptible strains (Table 1).

Investigation of the tap gene in KM-resistant strains revealed that almost all strains (except one strain) with Beijing genotype exhibited the insertion of cytosine between position 580 and 581 of the tap gene (Additional file 1: Table S1). This insertion caused a frameshift mutation and a premature stop codon, resulting in the 
Table 1 Genetic characterization of genes associated with KM resistance of KM-resistant and KM-susceptible M. tuberculosis strains

\begin{tabular}{|c|c|c|c|c|c|c|c|c|}
\hline \multirow[t]{2}{*}{ No. of strains } & \multicolumn{3}{|c|}{ MIC $(\mu \mathrm{g} / \mathrm{ml})$} & \multicolumn{5}{|c|}{ Gene/Mutation } \\
\hline & AK & KM & CAP & $r r s$ & eis & tap & whiB7 & tlyA \\
\hline \multicolumn{9}{|l|}{ KM resistant (29) } \\
\hline 1 & $>64$ & $>64$ & $>64$ & A1401G & wt & Ins581C & wt & $A 33 G^{b}$ \\
\hline 7 & $>64$ & $>64$ & 32 & A1401G & wt & Ins581C & wt & $A 33 G^{b}$ \\
\hline 5 & $>64$ & $>64$ & 32 & A1401G & wt & wt & wt & $A 33 G^{b}$ \\
\hline $4^{a}$ & $>64$ & $>64$ & 16 & A1401G & wt & Ins581C & wt & $A 33 G^{b}$ \\
\hline 2 & $>64$ & $>64$ & 16 & A1401G & wt & wt & wt & $A 33 G^{b}$ \\
\hline 1 & $>64$ & $>64$ & 4 & A1401G & wt & Ins581C & wt & $A 33 G^{b}$ \\
\hline 1 & 8 & 32 & 8 & A1401G & wt & Ins581C & wt & $A 33 G^{b}$ \\
\hline 1 & 8 & $>64$ & 8 & wt & $C-14 T$ & Ins581C & wt & $\mathrm{A} 33 \mathrm{G}^{\mathrm{b}}$ \\
\hline 1 & 8 & $>64$ & $>64$ & wt & $C-14 T$ & Ins581C & wt & $\mathrm{A} 33 \mathrm{G}^{\mathrm{b}} / \mathrm{Ins} 49 \mathrm{GC}$ \\
\hline $2^{\mathrm{a}}$ & 8 & $>64$ & $>64$ & wt & $C-14 T$ & Ins581C & wt & $\mathrm{A} 33 \mathrm{G}^{\mathrm{b}} / \mathrm{T} 539 \mathrm{G}$ \\
\hline 1 & 8 & $>64$ & $>64$ & wt & G-37 T & Ins581C & wt & $A 33 G^{b}$ \\
\hline 2 & $>64$ & $>64$ & 16 & wt & wt & Ins581C & wt & $\mathrm{A} 33 \mathrm{G}^{\mathrm{b}}$ \\
\hline $1^{\mathrm{a}}$ & $>64$ & $>64$ & 16 & wt & wt & wt & wt & $A 33 G^{b}$ \\
\hline \multicolumn{9}{|l|}{ KM susceptible (27) } \\
\hline 5 & $2-4$ & 4 & $2-4$ & wt & wt & Ins581C & wt & $A 33 G^{b}$ \\
\hline 22 & $2-4$ & 4 & $2-4$ & wt & wt & wt & wt & $A 33 G^{b}$ \\
\hline
\end{tabular}

${ }^{a}$ include one MDR-TB strain; ${ }^{b}$ no amino acid change.

production of a truncated protein (reduced in size from 419 to 231 amino acids). However, analysis of KMsusceptible strains also revealed this mutation (5 out of 27 strains) (Table 1 and Additional file 2: Table S2).

Sequence analysis of the $t$ ly $A$ gene revealed $\mathrm{A} \rightarrow \mathrm{G}$ nucleotide substitution at position 33 in all KM-resistant strains; however this mutation did not confer any amino acid change (Table 1 and Additional file 1: Table S1). Two CAP-resistant strains showed the $\mathrm{T} \rightarrow \mathrm{G}$ nucleotide substitution at position 539 of $t$ lyA that caused the amino acid change from lysine to arginine $(\mathrm{L} \rightarrow \mathrm{R})$ at codon 180 (Additional file 1: Table S1). One strain showed an insertion of GC at position 49, resulting in a frameshift mutation and the reduction of amino acid size from 268 to 26 amino acids (Additional file 1: Table S1). However, the A33G mutation, but not other tlyA mutations, was also found in all susceptible strains (Table 1 and Additional file 2: Table S2).

\section{Discussion}

In this study, the genetic mutations associated with resistance to AK, KM, and CAP were investigated in 26 XDR- and 3 MDR-TB strains isolated in Thailand. A nucleotide substitution from A to $\mathrm{G}$ at position 1401 (corresponding to position 1408 of the E. coli rrs gene) of the rrs gene is the most common mutation conferring high-level resistance to $\mathrm{AK}$ and $\mathrm{KM}$ in $M$. tuberculosis.
Although approximately 30-90\% of resistant strains contain this mutation [9-12], other mutations, including C1402T and G1484T, have also been reported [25-29]. The A1401G mutation has been preferentially used as a surrogate marker for resistance to AK and KM, whereas other rrs mutations are poor markers due to their presence in susceptible strains [30]. Our results revealed that the A1401G mutation was present in 21 of 29 KMresistant clinical strains, and no other $r$ rs mutations were identified (Table 1). Almost all of these strains (20 out of 21) had MICs $>64 \mu \mathrm{g} / \mathrm{ml}$ for both AK and KM while they showed broad MICs ranging from 4 to $64 \mu \mathrm{g} / \mathrm{ml}$ for CAP. This is consistent with previous studies reporting that the rrs A1401G mutation is the most common mechanism of KM resistance and correlates with highlevel resistance $[21,31,32]$. In addition, this mutation also confers cross-resistance to CAP [31]. The eight KMresistant strains lacking the rrs mutation showed highlevel resistance to $\mathrm{KM}(\mathrm{MIC}>64 \mu \mathrm{g} / \mathrm{ml})$, but five of them had a lower MIC for AK (MIC of $8 \mu \mathrm{g} / \mathrm{ml}$ ), indicating that other resistance determinants are involved in their resistance phenotype.

Investigation of other reported resistance mechanisms revealed that five of them had mutations in the promoter region of the eis gene, which encodes an aminoglycoside acetyltransferase (Table 1). This aminoglycoside acetyltransferase (Eis) catalyzes the transfer of an acetyl 
group from acetyl-coenzyme A to an amine group of aminoglycoside. It has been reported that Eis of $M$. tuberculosis shows a multiacetylation capability at the 2 '-, 3or $6^{\prime}$ positions of aminoglycoside antibiotics, resulting in an inactivation of many aminoglycoside antibiotics, including neamine, hygromycin, kanamycin, and amikacin [33]. In this study, all five strains harboring eis promoter mutations showed high-level KM resistance but lowlevel resistance to AK. The most identified mutation was $\mathrm{C}-14 \mathrm{~T}$ (4 of 5 strains). These mutations and other eis mutations, such as G-6 T, G-10A, C-12 T, A-13G and $\mathrm{C}-15 \mathrm{~T}$, have been previously shown to be associated with KM resistance [14,16,17]. Zaunbrecher et al. (2009) have reported that the major eis promoter mutations were G-10A and C-14 T [14]. Overexpression of eis resulting from the C-14 $\mathrm{T}$ mutation caused the highest levels of eis transcript, followed by G-37 T, G-10A, C-12 T and A-13G mutations [14]. In contrast to the previous study indicating that overexpression of eis confers low-level resistance to KM [14], our results revealed that the strains harboring eis mutation expressed high-level resistance to KM. One possible explanation is that these strains have additional unknown mechanisms contributing to their KM resistance, and these generate high-level resistance in combination with the eis mutation.

Other resistance determinants that are thought to be involved in resistance to $\mathrm{AK}, \mathrm{KM}$, and other structurally unrelated aminoglycosides (i.e., streptomycin) were also investigated in this study. The Tap protein is a putative multidrug efflux pump that was originally described in M. fortuitum [18]. Rv1258c encodes the homologous Tap protein in $M$. tuberculosis. Introduction of the tap gene from $M$. fortuitum into $M$. smegmatis conferred low-level resistance to tetracycline and aminoglycosides $[18,34,35]$. Our results revealed an insertion of cytosine between positions 580 and 581 of tap in 21 of 29 KMresistant strains. This mutation leads to a frameshift mutation at codon 194 resulting in the production of a truncated protein, reduced in size from 419 to 231 amino acids, that is likely to affect Tap activity. However, this insertion was also found in KM-susceptible clinical strains, suggesting that this protein is not associated with $\mathrm{AK}$ and $\mathrm{KM}$ resistance in M. tuberculosis. Interestingly, all of these tap mutation was found in the Beijing strains. This result was consistent with recent studies demonstrated that this type of mutation was found in all M. tuberculosis Beijing strains isolated from Russia, South Africa, the United Kingdom, and Spain [36,37] and confirmed the observation that an insertion of cytosine between positions 580 and 581 of tap is a polymorphism specific to the Beijing family of $M$. tuberculosis [37].

An association of WhiB7, a transcriptional regulator, with the expression of at least two antibiotic resistance genes, eis and tap has been demonstrated [19]. An increase in whiB7 expression, resulting from mutations located in the $5^{\prime}$ untranslated region (UTR), leads to upregulation of eis and tap, conferring low-level resistance to KM and streptomycin, respectively [13]. Investigation of this gene and its 5' UTR revealed no mutations in any KM-resistant and -susceptible strains. However, its expression level was not determined in this study.

Previous report revealed that lack of 2'-O-methyltranferase, which is encoded by tly $A$ and functions by methylation of specific nucleotides in 16S rRNA and 23S rRNA, resulted in CAP resistance [23]. Investigation of the tlyA showed that all tested strains had the A33G substitution without any amino acid changes, suggesting that this mutation is only nucleotide polymorphism and not associated with the resistant phenotype. Other tlyA mutations, T539G and Ins49GC, were found in two and one CAP-resistant strains, respectively, but were not found in all CAP-susceptible strains. These strains exhibited the high-level resistance to CAP with MIC greater than $64 \mu \mathrm{g} / \mathrm{ml}$ and did not contain the rrs mutation, indicating that these mutations were expectedly associated with CAP resistance [24]. Most recently, the T539G has been reported in capreomycin-resistant isolates in Korea but with low percentage (3 out of 86, 3.5\%) [38].

\section{Conclusions}

The most frequent AK- and KM-resistant mechanism in M. tuberculosis clinical strains isolated in Thailand was the rrs A1401G mutation ( 21 of 29 strains). This mutation correlated with high-level resistance to both AK and $\mathrm{KM}$, and also showed cross-resistance to CAP. Mutations of the eis promoter region are associated with low-level resistance to AK and found in 5 out of $29 \mathrm{KM}$ resistant strains. Two types of mutations at tlyA were found in this study and might be associated with CAP resistance. Identification of the resistant mechanisms, particularly a novel mechanism, is important for the development of surrogate markers that can be combined with other known resistance determinants to improve the rapid detection of drug-resistant $M$. tuberculosis strains.

\section{Methods}

\section{Mycobacterial strains and culture conditions}

Mycobacterium tuberculosis clinical strains (one strain per patient) were obtained from the Drug-Resistant Tuberculosis Research Laboratory, Drug-Resistant Tuberculosis Research Fund, Siriraj Foundation, Faculty of Medicine Siriraj Hospital, Mahidol University. They were isolated between 2004 and 2011 from new and previously treated patients with both known and unknown HIV status. This study was approved by the Siriraj Ethics Committee, Mahidol University, Bangkok, Thailand (Certificate of Approval No. Si 208/2005). The mycobacteria were cultured on 
Löwenstein-Jensen (LJ) medium (BBL, USA) and incubated at $37^{\circ} \mathrm{C}$ for 3-4 weeks. Species identification and antimycobacterial susceptibility testing were performed using in-house one-tube multiplex PCR [39] and the standard proportion method $[40,41]$, respectively.

\section{Isolation of genomic DNA}

One loop of mycobacterial cells grown on solid medium was scraped and suspended in $500 \mu \mathrm{l}$ of TE buffer (10 mM Tris- $\mathrm{HCl}$ (pH8.0), $1 \mathrm{mM}$ EDTA). The cells were inactivated by heating at $80^{\circ} \mathrm{C}$ for $20 \mathrm{~min}$ and subsequently harvested by centrifugation at $6,000 \mathrm{xg}$ at $4{ }^{\circ} \mathrm{C}$ for $10 \mathrm{~min}$. The cells were resuspended in $400 \mu \mathrm{l}$ of TrisEDTA-Tween-lysozyme solution $(10 \mathrm{mM}$ Tris- $\mathrm{HCl}$ (pH 8.0), $1 \mathrm{mM}$ EDTA, 0.5\% (v/v) Tween $80,2 \mathrm{mg} / \mathrm{ml}$ lysozyme (Amresco, USA)), and the mixtures were then incubated at $37^{\circ} \mathrm{C}$ for $3 \mathrm{~h}$. SDS and proteinase $\mathrm{K}$ were added to the cell suspension to generate final concentrations of $1 \%(\mathrm{w} / \mathrm{v})$ and $1 \mathrm{mg} / \mathrm{ml}$, respectively, prior to incubation at $37^{\circ} \mathrm{C}$ for $1 \mathrm{~h}$. Then, $80 \mu \mathrm{l}$ of $5 \mathrm{M} \mathrm{NaCl}$ and $80 \mu \mathrm{l}$ of $10 \%(\mathrm{w} / \mathrm{v})$ cetyl trimethyl ammonium bromide (CTAB) (Sigma, USA) were added to the suspension, and the suspension was immediately heated at $65^{\circ} \mathrm{C}$ for
15 min. An equal volume of chloroform-isoamyl alcohol $(24: 1)(\mathrm{v} / \mathrm{v})$ was added to the suspension. The aqueous DNA phase was separated by centrifugation at $12,000 \mathrm{xg}$ for $5 \mathrm{~min}$ and mixed again with an equal volume of chloroform-isoamyl alcohol (24:1) (v/v). DNA was precipitated by adding 0.1 volume of $3 \mathrm{M}$ sodium acetate ( $\mathrm{pH} 5.3$ ) and 2.5 volumes of ice-chilled absolute ethanol, followed by incubation at $-70^{\circ} \mathrm{C}$ for $30 \mathrm{~min}$. DNA was separated by centrifugation at $12,000 \mathrm{xg}$ at $4{ }^{\circ} \mathrm{C}$ for $15 \mathrm{~min}$. Total nucleic acid was washed once with $500 \mu \mathrm{l}$ of ice-chilled $70 \%$ ethanol, dried, and resuspended in $20 \mu \mathrm{l}$ of TE buffer. RNaseA (Qiagen, Germany) was added to the total nucleic acid solution to generate a final concentration of $0.5 \mu \mathrm{g} / \mu \mathrm{l}$, and the tube was subsequently incubated at $37^{\circ} \mathrm{C}$ for $1 \mathrm{~h}$.

\section{DNA amplification}

The rrs (Rvnr01), eis (Rv2416c), whiB7 (Rv3197A), tap (Rv1258c), and tlyA (Rv1694) genes were amplified by PCR using specific primers (Table 2). PCR was performed in a $50-\mu \mathrm{l}$ reaction mixture containing $20 \mathrm{mM}$ Tris- $\mathrm{HCl}$ (pH 8.4), $50 \mathrm{mM} \mathrm{KCl}, 1.5 \mathrm{mM} \mathrm{MgCl} 2,200 \mu \mathrm{M}$ of each dNTP, $0.5 \mu \mathrm{M}$ of each primer, $50 \mathrm{ng}$ of DNA template, and 2.5 U of Taq DNA polymerase (Promega, USA). The PCR

Table 2 Primers used for amplification and sequencing of M.tuberculosis clinical strains

\begin{tabular}{|c|c|c|c|c|c|c|}
\hline Gene & $\begin{array}{l}\text { Primer name } \\
(\text { position*) }\end{array}$ & $\begin{array}{l}\text { Primer sequence } \\
\qquad\left(5^{\prime} \rightarrow 3^{\prime}\right)\end{array}$ & $\begin{array}{l}\text { Annealing } \\
\text { temp }\left({ }^{\circ} \mathrm{C}\right)\end{array}$ & $\begin{array}{l}\text { PCR product } \\
\text { size (bp) }\end{array}$ & Purpose & Reference \\
\hline \multirow[t]{6}{*}{ rrs } & F-rrs $(-44)$ & 5'-TTCTAAATACCTITGGCTCCCT-3' & 51 & 1,680 & PCR/Seq & {$[42]$} \\
\hline & R-rrs $(1,636)$ & 5'-TGGCCAACTITGTTGTCATGCA-3' & 53 & & $\mathrm{PCR} / \mathrm{Seq}$ & {$[42]$} \\
\hline & F-rrs1 (554) & 5'-CTGGGCGTAAAGAGCTCGTA-3' & 54 & & Seq & This study \\
\hline & F-rrs2 $(1,114)$ & 5'-GTTGCCAGCACGTAATGGTG-3' & 54 & & Seq & This study \\
\hline & R-rrs1 (483) & 5'-TCCACCTACCGTCAATCCGA-3' & 54 & & Seq & This study \\
\hline & R-rrs2 $(1,073)$ & 5'-ATCTCACGACACGAGCTGAC-3' & 54 & & Seq & This study \\
\hline \multirow[t]{6}{*}{ eis (Rv2416c) } & F-Rv2417c (-316) & 5'-GCGGTGCATCACGTCGCCGA-3' & 60 & 1,661 & PCR/Seq & This study \\
\hline & R-eis-Rv2415c $(1,345)$ & 5'-GCAACGCGATCCGCGAGTGC-3' & 60 & & PCR/Seq & This study \\
\hline & F-eis1 (247) & 5'-AGTTTCGTCGCGGTGGCGCC-3' & 60 & & Seq & This study \\
\hline & F-eis2 (816) & 5'-GGACCCGTTACCCCACCTGC-3' & 60 & & Seq & This study \\
\hline & R-eis1 (240) & 5'-GGCGGTCGGGAGCACCACTT-3' & 60 & & Seq & This study \\
\hline & R-eis2 (769) & 5'-TCAGGGCCCGCCACAACGCA-3' & 60 & & Seq & This study \\
\hline \multirow[t]{6}{*}{$\operatorname{tap}(\mathrm{Rv} 1258 \mathrm{c})$} & F-Rv1259 (-496) & 5'-CAGGCCGGCCCTATGCAGTG-3' & 60 & 1,847 & PCR/Seq & This study \\
\hline & $R-\operatorname{Rv} 1257 c(1,351)$ & 5'-CGGTCTTGCCGGTAGCCGTC-3' & 60 & & $\mathrm{PCR} / \mathrm{Seq}$ & This study \\
\hline & F-tap1 (41) & 5'-TCGCAACGCTGATGGCGGCC-3' & 60 & & Seq & This study \\
\hline & F-tap2 (641) & 5'-AGGGGCTGCGCTTCGTCTGG-3' & 60 & & Seq & This study \\
\hline & R-tap1 (210) & 5'-CCCGAAGTAGTCGACCGCGG-3' & 60 & & Seq & This study \\
\hline & R-tap2 (862) & 5'-GACGGGGAACGCGGATAGCC-3' & 60 & & Seq & This study \\
\hline \multirow[t]{2}{*}{ whiB7 (Rv3197A) } & F URT-whiB7 (-451) & 5'-GCTGGTTCGCGGTCGGACCT-3' & 60 & 550 & PCR/Seq & This study \\
\hline & R whiB7 (99) & 5'-CGGGGTATCGGCGAACCACA-3' & 58 & & PCR/Seq & This study \\
\hline \multirow[t]{2}{*}{ tlyA (Rv1694) } & F-tlyA (1) & 5'-GTGGCACGACGTGCCCGCGT-3' & 62 & 807 & PCR/Seq & This study \\
\hline & R-tlyA (807) & 5'-CTACGGGCCCTCGCTAATCG-3' & 58 & & PCR/Seq & This study \\
\hline
\end{tabular}

*The first 5 'nucleotide position of each primer was counted from the translation start codon of each gene. 
conditions consisted of an initial denaturation at $94^{\circ} \mathrm{C}$ for $5 \mathrm{~min}$, followed by 35 cycles of denaturation at $94^{\circ} \mathrm{C}$ for $30 \mathrm{sec}$, annealing at $56-60^{\circ} \mathrm{C}$ for $1 \mathrm{~min}$ and extension at $72^{\circ} \mathrm{C}$ for $1-2$ min depending on the PCR product size (Table 2), and a final extension at $72^{\circ} \mathrm{C}$ for $7 \mathrm{~min}$. The PCR products were analyzed by agarose gel electrophoresis and purified using the QIAquick PCR Purification Kit (Qiagen, Germany) prior to submission for DNA sequencing.

\section{DNA sequencing analysis}

Nucleotide sequencing was performed with the Big-Dye ${ }^{\mathrm{Tx}}$ Terminator Cycle Sequencing Ready Reaction Kit (Perkin Elmer, USA) using an ABI PRISM ${ }^{\mathrm{R}} 3700$ DNA analyzer at First BASE Laboratories (Malaysia). The PCR products were sequenced in both directions. The obtained nucleotide sequences were compared with those of $M$. tuberculosis H37Rv (Accession no. NC_000962) by pairwise alignment using the ClustalW program [43].

\section{Drug susceptibility testing and determination of minimal inhibitory concentrations (MICs)}

The susceptibility testing was achieved by the disc diffusion method on the Middlebrook 7H10 agar (Difco, USA) supplemented with $10 \%$ oleic acid-albumin-dextrose-catalase (OADC) with a single concentration of drug as recommended by the CLSI [41]. The MICs of AM, KM, and CAP were determined by the agar dilution method according to CLSI guidelines [41] on Middlebrook 7H10 agar supplemented with $10 \%$ OADC and various concentrations of drug $(0,2,4,8,16,32$, and $64 \mu \mathrm{g} / \mathrm{ml})$. AK, KM, and CAP were purchased from Sigma Aldrich (Germany). The MIC was defined as the lowest concentration of drug that inhibited growth $(>99 \%)$ after 4 weeks of incubation at $37^{\circ} \mathrm{C}$. M. tuberculosis H37Rv ATCC 27294 was used as the susceptible control strain. Three independent experiments were performed for each strain.

\section{Additional files}

Additional file 1: Table S1. Genetic characterization of resistance genes and MIC values for amikacin, kanamycin and capreomycin in $29 \mathrm{KM}$-resistant clinical isolates of $M$. tuberculosis.

Additional file 2: Table S2. Genetic characterization of resistance genes and MIC values for amikacin, kanamycin and capreomycin in $27 \mathrm{AK}$ - and KM-susceptible clinical isolates of $M$. tuberculosis.

\section{Competing interests}

The authors declare that they have no competing interests.

\section{Authors' contributions}

AS performed all experiments in this study and drafted the manuscript. AS, TP, and SP analyzed the results and formatted the data. TP and SP conceptualized and designed the experimental procedures, supervised all the experimental works, corrected and produced the final version of the manuscript. AC provided clinical MTB strains from Thai patients. SP provided funding and grant. All authors read and approved the final manuscript.

\section{Acknowledgements}

This study was financially supported by the Faculty of Science, King Mongkut's Institute of Technology Ladkrabang (KMITL) and the Drug-Resistant Tuberculosis Research Fund, Siriraj Foundation, Faculty of Medicine Siriraj Hospital, Mahidol University. A. Sowajassatakul is also thankful for a scholarship for the Ph.D. Program that was provided by the Thailand Graduate Institute of Science and Technology (TGIST), National Science and Technology Development Agency (NSTDA).

\section{Author details}

${ }^{1}$ Department of Biology, Faculty of Science, King Mongkut's Institute of Technology Ladkrabang, Bangkok 10520, Thailand. 'Tuberculosis Research Laboratory, National Center for Genetic Engineering and Biotechnology, National Science and Technology Development Agency, Thailand Science Park, Pathumthani 12120, Thailand. ${ }^{3}$ Department of Microbiology, Faculty of Medicine Siriraj Hospital, Mahidol University, Bangkok 10700, Thailand. ${ }^{4}$ Drug Resistance Tuberculosis Research Fund, Siriraj Foundation, Bangkok 10700, Thailand.

Received: 28 February 2014 Accepted: 17 June 2014

Published: 22 June 2014

\section{References}

1. WHO: Global tuberculosis report; 2013. WHO/HTM/TB/2013.11. Geneva. 2013.

2. Blakemore R, Story E, Helb D, Kop J, Banada P, Owens MR, Chakravorty S, Jones $M$, Alland D: Evaluation of the analytical performance of the Xpert MTB/RIF assay. J Clin Microbiol 2010, 48(7):2495-2501.

3. Boehme CC, Nabeta P, Hillemann D, Nicol MP, Shenai S, Krapp F, Allen J, Tahirli R, Blakemore R, Rustomjee R, Milovic A, Jones M, O'Brien SM, Persing DH, Ruesch-Gerdes S, Gotuzzo E, Rodrigues C, Alland D, Perkins MD: Rapid molecular detection of tuberculosis and rifampin resistance. $N$ Engl J Med 2010, 363(11):1005-1015.

4. Helb D, Jones M, Story E, Boehme C, Wallace E, Ho K, Kop J, Owens MR, Rodgers R, Banada P, Safi H, Blakemore R, Lan NTN, Jones-López EC, Levi M, Burday M, Ayakaka I, Mugerwa RD, McMillan B, Winn-Deen E, Christel L, Dailey P, Perkins MD, Persing DH, Alland D: Rapid detection of Mycobacterium tuberculosis and rifampin resistance by use of on-demand, near-patient technology. J Clin Microbiol 2010, 48(1):229-237.

5. Hillemann D, Rüsch-Gerdes S, Richter E: Evaluation of the GenoType MTBDRplus assay for rifampin and isoniazid susceptibility testing of Mycobacterium tuberculosis strains and clinical specimens. J Clin Microbiol 2007, 45(8):2635-2640.

6. Jin J, Zhang Y, Fan X, Diao N, Shao L, Wang F, Hu P, Wang S, Weng $X$, Zhang W: Evaluation of the GenoType ${ }^{\circledR}$ MTBDRplus assay and identification of a rare mutation for improving MDR-TB detection. Int J Tuberc Lung Dis 2012, 16(4):521-526.

7. Lacoma A, Garcia-Sierra N, Prat C, Ruiz-Manzano J, Haba L, Rosés S, Maldonado J, Domínguez J: GenoType MTBDRplus assay for molecular detection of rifampin and isoniazid resistance in Mycobacterium tuberculosis strains and clinical samples. J Clin Microbiol 2008, 46(11):3660-3667

8. Recht MI, Douthwaite S, Puglisi JD: Basis for prokaryotic specificity of action of aminoglycoside antibiotics. EMBO J 1999, 18(11):3133-3138.

9. Ajbani K, Rodrigues C, Shenai S, Mehta A: Mutation detection and accurate diagnosis of extensively drug-resistant tuberculosis: report from a tertiary care center in India. J Clin Microbio/ 2011, 49(4):1588-1590.

10. Evans J, Segal H: Novel multiplex allele-specific PCR assays for the detection of resistance to second-line drugs in Mycobacterium tuberculosis. J Antimicrob Chemother 2010, 65(5):897-900.

11. Perdigão J, Macedo R, Malaquias A, Ferreira A, Brum L, Portugal I: Genetic analysis of extensively drug-resistant Mycobacterium tuberculosis strains in Lisbon, Portugal. J Antimicrob Chemother 2010, 65(2):224-227.

12. Yuan X, Zhang T, Kawakami K, Zhu J, Li H, Lei J, Tu S: Molecular characterization of multidrug- and extensively drug-resistant Mycobacterium tuberculosis strains in Jiangxi, China. J Clin Microbiol 2012, 50(7):2404-2413.

13. Reeves AZ, Campbell PJ, Sultana R, Malik S, Murray M, Plikaytis BB, Shinnick TM, Posey JE: Aminoglycoside cross-resistance in Mycobacterium tuberculosis due to mutations in the $5^{\prime}$ untranslated region of whiB7. Antimicrob Agents Chemother 2013, 57(4):1857-1865. 
14. Zaunbrecher MA, Sikes RD, Metchock B, Shinnick TM, Posey JE: Overexpression of the chromosomally encoded aminoglycoside acetyltransferase eis confers kanamycin resistance in Mycobacterium tuberculosis. Proc Natl Acad Sci U S A 2009, 106(47):20004-20009.

15. Campbell PJ, Morlock GP, Sikes RD, Dalton TL, Metchock B, Starks AM, Hooks DP, Cowan LS, Plikaytis BB, Posey JE: Molecular detection of mutations associated with first- and second-line drug resistance compared with conventional drug susceptibility testing of Mycobacterium tuberculosis. Antimicrob Agents Chemother 2011, 55(5):2032-2041.

16. Engström A, Perskvist N, Werngren J, Hoffner SE, Juréen P: Comparison of clinical isolates and in vitro selected mutants reveals that tlyA is not a sensitive genetic marker for capreomycin resistance in Mycobacterium tuberculosis. J Antimicrob Chemother 2011, 66(6):1247-1254.

17. Gikalo MB, Nosova EY, Krylova LY, Moroz AM: The role of eis mutations in the development of kanamycin resistance in Mycobacterium tuberculosis isolates from the Moscow region. J Antimicrob Chemother 2012, 67(9):2107-2109.

18. Aínsa JA, Blokpoel MCJ, Otal I, Young DB, De Smet KAL, Martín C: Molecular cloning and characterization of Tap, a putative multidrug efflux pump present in Mycobacterium fortuitum and Mycobacterium tuberculosis. J Bacteriol 1998, 180(22):5836-5843.

19. Morris RP, Nguyen L, Gatfield J, Visconti K, Nguyen K, Schnappinger D, Ehrt S, Liu Y, Heifets L, Pieters J, Schoolnik G, Thompson CJ: Ancestral antibiotic resistance in Mycobacterium tuberculosis. Proc Natl Acad Sci U S A 2005, 102(34):12200-12205.

20. Maus CE, Plikaytis BB, Shinnick TM: Molecular analysis of cross-resistance to capreomycin, kanamycin, amikacin, and viomycin in Mycobacterium tuberculosis. Antimicrob Agents Chemother 2005, 49(8):3192-3197.

21. Via LE, Cho SN, Hwang S, Bang H, Park SK, Kang HS, Jeon D, Min SY, Oh T, Kim Y, Kim YM, Rajan V, Wong SY, Shamputa IC, Carroll M, Goldfeder L, Lee SA, Holland SM, Eum S, Lee H, Barry CE: Polymorphisms associated with resistance and cross-resistance to aminoglycosides and capreomycin in Mycobacterium tuberculosis isolates from south korean patients with drug-resistant tuberculosis. J Clin Microbiol 2010, 48(2):402-411.

22. Akbergenov R, Shcherbakov D, Matt T, Duscha S, Meyer M, Wilson DN, Böttger EC: Molecular basis for selectivity of antituberculosis compounds capreomycin and viomycin. Antimicrob Agents Chemother 2011, 55(10):4712-4717

23. Johansen SK, Maus CE, Plikaytis BB, Douthwaite S: Capreomycin binds across the ribosomal subunit interface using tlyA-encoded 2'-Omethylations in $16 \mathrm{~S}$ and $23 \mathrm{~S}$ rRNAs. Mol Cell 2006, 23(2):173-182.

24. Maus CE, Plikaytis BB, Shinnick TM: Mutation of tlyA confers capreomycin resistance in Mycobacterium tuberculosis. Antimicrob Agents Chemother 2005, 49(2):571-577.

25. Brossier F, Veziris N, Aubry A, Jarlier $V$, Sougakoff W: Detection by GenoType MTBDRs/ test of complex mechanisms of resistance to second-line drugs and ethambutol in multidrug-resistant Mycobacterium tuberculosis complex isolates. J Clin Microbiol 2010, 48(5):1683-1689.

26. Feuerriegel S, Cox HS, Zarkua N, Karimovich HA, Braker K, Rüsch-Gerdes S, Niemann S: Sequence analyses of just four genes to detect extensively drug-resistant Mycobacterium tuberculosis strains in multidrug-resistant tuberculosis patients undergoing treatment. Antimicrob Agents Chemother 2009, 53(8):3353-3356

27. Kiet VS, Lan NTN, An DD, Dung NH, Hoa DV, Chau NV, Chinh NT, Farrar J Caws M: Evaluation of the MTBDRsl test for detection of second-linedrug resistance in Mycobacterium tuberculosis. J Clin Microbiol 2010, 48(8):2934-2939

28. Sirgel FA, Tait M, Warren RM, Streicher EM, Böttger EC, Van Helden PD, Gey Van Pittius NC, Coetzee G, Hoosain EY, Chabula-Nxiweni M, Hayes C, Victor TC, Trollip A: Mutations in the rrs A1401G gene and phenotypic resistance to amikacin and capreomycin in Mycobacterium tuberculosis. Microb Drug Resist 2012 2012, 18(2):193-197.

29. Suzuki Y, Katsukawa C, Tamaru A, Abe C, Makino M, Mizuguchi Y, Taniguchi H: Detection of kanamycin-resistant Mycobacterium tuberculosis by identifying mutations in the 16S rRNA gene. J Clin Microbio/ 1998, 36(5):1220-1225.

30. Georghiou SB, Magana M, Garfein RS, Catanzaro DG, Catanzaro A, Rodwell TC. Evaluation of genetic mutations associated with Mycobacterium tuberculosis resistance to amikacin, kanamycin and capreomycin: a systematic review. PLoS One 2012, 7(3):e33275.

31. Jugheli L, Bzekalava N, Rijk PD, Fissette K, Portaels F, Rigouts L: High level of cross-resistance between kanamycin, amikacin and capreomycin among
Mycobacterium tuberculosis isolates from Georgia and a close relation with mutations in the rrs gene. Antimicrob Agents Chemother 2009, 53(12):5064-5068.

32. Krüüner $A$, Jureen $P$, Levina $K$, Ghebremichael $S$, Hoffner S: Discordant resistance to kanamycin and amikacin in drug-resistant Mycobacterium tuberculosis. Antimicrob Agents Chemother 2003, 47(9):2971-2973.

33. Chen W, Biswas T, Porter VR, Tsodikov OV, Garneau-Tsodikova S: Unusual regioversatility of acetyltransferase Eis, a cause of drug resistance in XDR-TB. Proc Natl Acad Sci U S A 2011, 108(24):9804-9808.

34. De Rossi E, Arrigo P, Bellinzoni M, Silva PEA, Martin C, Aínsa JA, Guglierame P, Riccardi G: The multidrug transporters belonging to major facilitator superfamily (MFS) in Mycobacterium tuberculosis. Mol Med 2002, 8(11):714-724.

35. Siddiqi N, Das R, Pathak N, Banerjee S, Ahmed N, Katoch VM, Hasnain SE: Mycobacterium tuberculosis isolate with a distinct genomic identity overexpresses a Tap-like efflux pump. Infection 2004, 32(2):109-111.

36. Köser CU, Bryant JM, Parkhill J, Peacock SJ: Consequences of whiB7 (Rv3197A) mutations in Beijing genotype isolates of the Mycobacterium tuberculosis complex. Antimicrob Agents Chemother 2013, 57(7):3461.

37. Villellas C, Aristimuño L, Vitoria M-A, Prat C, Blanco S, de Viedma DG, Domínguez J, Samper S, Aínsa JA: Analysis of mutations in streptomycinresistant strains reveals a simple and reliable genetic marker for identification of the Mycobacterium tuberculosis Beijing genotype. J Clin Microbio/ 2013, 51(7):2124-2130.

38. Jnawali HN, Yoo H, Ryoo S, Lee KJ, Kim BJ, Koh WJ, Kim CK, Kim HJ, Park YK: Molecular genetics of Mycobacterium tuberculosis resistant to aminoglycosides and cyclic peptide capreomycin antibiotics in Korea. World J Microbiol Biotechnol 2013, 29(6):975-982.

39. Chaiprasert A, Prammananan T, Tingtoy N, Na-Ubol P, Srimuang S, Samerpitak K, Rangsipanuratn W: One-tube multiplex PCR method for rapid identification of Mycobacterium tuberculosis. Southeast Asian J Trop Med Publ Health 2006, 37(3):494-502.

40. Laszlo A, Rahman M, Espinal M, Raviglione M: Quality assurance programme for drug susceptibility testing of Mycobacterium tuberculosis in the WHO/ IUATLD supranational reference laboratory network: Five rounds of proficiency testing, 1994-1998. Int J Tuberc Lung Dis 2002, 6(9):748-756.

41. National Committee for Clinical Laboratory Standards: Susceptibility testing of Mycobacteria, Nocardiae, and other aerobic Actinomycetes; Approved standard. Wayne, PA: Document M24-A, National Committee for Clinical Laboratory Standards; 2003

42. Daum LT, Rodriguez JD, Worthy SA, Ismail NA, Omar SV, Dreyer AW, Fourie PB, Hoosen AA, Chambers JP, Fischer GW: Next-generation ion torrent sequencing of drug resistance mutations in Mycobacterium tuberculosis strains. $J$ Clin Microbiol 2012, 50(12):3831-3837.

43. Thompson JD, Higgins DG, Gibson TJ: CLUSTAL W: improving the sensitivity of progressive multiple sequence alignment through sequence weighting position-specific gap penalties and weight matrix choice. Nucl Acids Res 1994, 22(22):4673-4680.

doi:10.1186/1471-2180-14-165

Cite this article as: Sowajassatakul et al:: Molecular characterization of amikacin, kanamycin and capreomycin resistance in M/XDR-TB strains isolated in Thailand. BMC Microbiology 2014 14:165

\section{Submit your next manuscript to BioMed Central and take full advantage of:}

- Convenient online submission

- Thorough peer review

- No space constraints or color figure charges

- Immediate publication on acceptance

- Inclusion in PubMed, CAS, Scopus and Google Scholar

- Research which is freely available for redistribution 